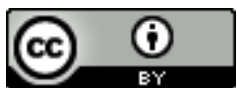

\title{
PRÁTICAS PEDAGÓGICAS INOVADORAS NA FORMAÇÃO DOCENTE: CIBORGUIZAÇÃO dO CURRíCULO dO CURSO DE PEDAGOGIA
}

\begin{tabular}{c}
\hline INNOVATIVE PEDAGOGICAL PRACTICES IN TEACHING TRAINING: \\
CIBORGUIZATION OF THE CURRICULUM OF THE COURSE OF PEDAGOGY \\
PRÁCTICAS PEDAGÓGICAS INNOVADORAS EN LA FORMACIÓN DOCENTE: \\
CIBORGUIZACIÓN DEL CURRÍCULO DEL CURSO DE PEDAGOGÍA \\
\hline
\end{tabular}

\section{Shirlei Rezende Sales ${ }^{\mathrm{i}}$ \\ Rafaela Esteves Godinho Leal}

\begin{abstract}
RESUMO: Vivemos em um contexto de rápidas transformações em inúmeras práticas sociais. Dentre elas, merece destaque a incorporação das tecnologias digitais nos processos cotidianos da condução da vida. Crianças e jovens estão cada vez conectadas/os ao ciberespaço. Temos uma geração ciborgue. Para atender às necessidades dessa geração, reivindica-se dentre outras coisas, uma formação docente que prepare efetivamente as/os novas/os professoras/es para o trabalho com esses sujeitos da contemporaneidade. Buscando atender a essa demanda, o objetivo do trabalho aqui relatado foi ciborguizar a formação docente. Para isso, as metodologias desenvolvidas incorporaram as tecnologias digitais nas atividades curriculares do curso de graduação em Pedagogia, alcançando 150 licenciandas/os. Nas práticas curriculares inovadoras aqui analisadas utilizaram-se diversificadas ferramentas tecnológicas para favorecer a aprendizagem efetiva e contribuir para a produção de conteúdo colaborativo. Conclui-se que a ciborguização curricular tende a favorecer os processos de aprendizagem das/os futuras/os docentes, motivando-as/os e aumentando o envolvimento delas/es com sua própria formação, além de prepará-las/os para inserir as tecnologias digitais no contexto da Educação Básica.
\end{abstract}

PALAVRAS-ChAVE: Formação de professores. Tecnologias digitais. Inovação. Currículo. Ciborguização.

ABSTRACT: We live in a context of rapid transformation in countless social practices. Among them, it is worth highlighting the incorporation of digital technologies in the daily processes of life conduction. Children and young people are increasingly connected to cyberspace. We have a cyborg generation. To meet the needs of this generation, it is claimed, among other things, a teacher training that effectively prepares the new teachers to work with these contemporaries. In order to meet this demand, the objective of the work reported in this paper was to cyborg the teacher training. For this, the methodologies developed incorporated the digital technologies in the curricular activities of the graduation course in Pedagogy, reaching 150 graduates. In the innovative curricular practices analyzed here, we used a variety of technological tools to favor effective learning and contribute to the production of collaborative content. It is concluded that curricular cyborgization tends to favor the learning processes of future teachers, motivating them and increasing their involvement with their own formation, as well as preparing them to insert digital technologies in the context of Basic Education.

KEYWORDS: Teacher training. Digital technologies. Innovation. Curriculum. Cyborgization.

RESUMEN: Vivimos en un contexto de rápidas transformaciones en innumerables prácticas sociales. Entre ellas, merece destacarse la incorporación de las tecnologías digitales en los procesos cotidianos de la conducción de la vida. Los niños y jóvenes están cada vez conectados al ciberespacio. Tenemos una generación ciborgue. Para atender a las necesidades de esa generación, se reivindica entre otras cosas, una formación docente que prepare efectivamente a las/los jóvenes las/los profesoras/es para el trabajo con esos sujetos de la contemporaneidad. En busca de atender a esa demanda, el objetivo del trabajo aquí relatado fue cibernizar la formación docente. Para

Submetido em: 25/08/2017 - Aceito em: 01/10/2017 - Publicado em: 15/10/2017.

\begin{tabular}{l|l|l|l|l|l|}
\hline C Rev. Inter. Educ. Sup. & Campinas, SP & v.4 & n.1 & p.6-24 & jan./abr. 2018 \\
\hline
\end{tabular}


ello, las metodologías desarrolladas incorporaron las tecnologías digitales en las actividades curriculares del curso de graduación en Pedagogía, alcanzando 150 licenciandas/os. En las prácticas curriculares innovadoras aquí analizadas se utilizaron diversas herramientas tecnológicas para favorecer el aprendizaje efectivo y contribuir a la producción de contenido colaborativo. Se concluye que la ciborguización curricular tiende a favorecer los procesos de aprendizaje de las/los futuros docentes, motivando-las/los y aumentando la participación de ellas con su propia formación, además de prepararlas para insertar las tecnologías Digitales en el contexto de la Educación Básica.

PALABRAS CLAVE: Formación de profesores. Tecnologías digitales. Innovación. El currículo. Ciborguización.

\section{INTRODUÇÃO}

$\mathrm{Na}$ contemporaneidade, parece haver um imperativo do uso das tecnologias digitais nas práticas mais cotidianas. Elas têm operado mudanças nas atividades mais corriqueiras dos sujeitos na sociedade, tendo efeitos, inclusive, nos processos de ensino-aprendizagem na universidade. Isso pode ser exemplificado em frases proferidas por professoras/es universitárias/os, tais como: "há de se abrir e utilizar cada vez mais das tecnologias de forma criativa. Não há como retroceder...e nem queremos isso” (LEAL, 2017, p. 93). Nesse sentido, as tecnologias digitais parecem funcionar como um imperativo nas aulas na universidade. Contudo, elas também se apresentam como ameaçadoras: "um dos principais problemas para mim durante as classes é que os alunos estão o tempo todo olhando, verificando seus telefones celulares e smartphones enquanto estou ministrando as aula"(LEAL, 2017, p. 99).

Nesse contexto, os currículos da educação básica e superior têm sido alvo do que podemos denominar de "imperativo da ciborguização" (SALES, 2013). A ciborguização consiste na composição híbrida entre práticas analógicas e práticas digitais. O currículo ciborgue (GREEN; BIGUM, 2003) já é uma realidade entre nós. "Ele surge da complexificação e transformação dos planejamentos e das práticas curriculares por meio da intensiva e extensiva incorporação/fusão com as tecnologias digitais" (SALES, 2014, p. 231). Um dos efeitos disso é a sensação de que não há escape. A presença das tecnologias digitais nos currículos escolares parece inevitável.

Tal presença não é da ordem da simples morada. Na verdade, as tecnologias operam mudanças no currículo, demandam outros modos de planejar, outras formas de organizar os saberes. Afinal, produzem outras formas de conhecer e outros tipos de conhecimento. As tecnologias exigem a ciborguização do currículo escolar. $\mathrm{O}$ currículo ciborgue é, portanto, um produto da simbiose das práticas curriculares com as tecnologias digitais (SALES, 2014, p. 231).

No entanto, mesmo diante do imperativo da ciborguização, muitas escolas ainda demonizam as tecnologias e tentam bani-las da sala de aula. As alegações para esses procedimentos são as mais variadas. Normalmente acusa-se as tecnologias de desconcentrarem as/os alunas/os, como se elas fossem concorrentes das práticas escolares. Parece haver uma tentativa 
nostálgica de garantir práticas curriculares tradicionais, baseadas no silêncio, na concentração máxima e na realização de uma tarefa por vez.

Instala-se, assim, uma espécie de desajuste: "enquanto a juventude ciborgue se conecta cada vez mais visceral e intimamente com as tecnologias digitais, a escola insiste em métodos analógicos, tornando-se gradativamente mais incompatível com os seres que a habitam" (SALES, 2014, p. 243). Diante desse contexto de transformações sociais e do imperativo da ciborguização curricular, somos instigadas/os a pensar: "qual é a capacidade de a escola resistir a semelhante mutação, e se essa estrutura envelhecida estará em condições de se adaptar às novas regras do jogo, transformando-se de um modo efetivo e interessante?" (SIBÍLIA, 2012, p.179).

Outra questão importante a ser considerada é a eterna disputa em torno de quem detém o conhecimento, afinal, o imperativo da ciborguização tem modificado a dinâmica das relações de poder entre mestres e alunas/os, em que geralmente as/os docentes estão em clara posição de desvantagem. A soberania no ciberespaço tem sido comumente das/os mais jovens. Afinal, de modo geral, os jovens têm um grau mais elevado de ciborguização do que as/os docentes. Comumente, a juventude ciborgue é mais fluente no ciberespaço do que as/os professoras/es e isso "coloca em xeque as relações de poder e as hierarquias de saber na sala de aula. É como se a cibercultura ameaçasse o status do docente enquanto exclusivo detentor do conhecimento" (SALES, 2014, p. 235). Diante disso, a escola entra em embate com a cibercultura, chegando a desqualificar ou até mesmo tentar proibir suas práticas.

Esse processo de demonização das tecnologias na escola, em um contexto de intensificação de seu uso em outras instâncias da vida, parece um contrassenso e fragiliza a relação das/os estudantes com a instituição escolar. Para se contrapor a isso, demanda-se a elaboração de práticas curriculares no âmbito da formação docente, que possam atender ao imperativo da ciborguização. O relato aqui apresentado, analisa o trabalho desenvolvido em um curso de formação docente, com o objetivo de ciborguizar a formação docente e com isso preparar as/os futuras/os professoras/es para o exercício profissional, utilizando práticas que possam estar em consonância com as demandas das/os alunas/os da contemporaneidade.

As crianças e jovens que hoje se encontram nas escolas de educação básica têm sua existência modificada pela íntima conexão com as tecnologias digitais. Isso exige que as/es professoras/es sejam preparadas/os para lidar com esses novos sujeitos, com suas habilidades modificadas, com suas inusitadas formas de pensar e conhecer. Portanto, os cursos de formação docente devem contemplar esses aspectos.

O projeto de trabalho aqui sistematizado foi desenvolvido nos dois semestres letivos de 2014, com quatro turmas do curso de graduação em Pedagogia da Universidade Federal de Minas Gerais, atingindo 150 licenciandas/os. O objetivo foi ciborguizar a formação docente, por meio da incorporação de tecnologias digitais no desenvolvimento das atividades curriculares.

(C) Rev. Inter. Educ. Sup.

\begin{tabular}{l|r} 
Campinas, SP & v.4
\end{tabular}

n.1 p.6-24 jan./abr. 2018 
Isso foi feito visando a desenvolver práticas curriculares em que sejam incorporadas as tecnologias digitais, de modo a superar a oposição entre currículo escolar e tecnologia.

As/Os alunas/os do curso de graduação, em sua maioria, jovens têm seus próprios modos de aprender alterados pela conexão com as tecnologias digitais. Parte significativa das/os cursistas do ensino superior, já opera o pensamento de modo diferenciado e demanda de nós, professoras/es universitárias/os, outras formas de ensinar que levem em conta essas diversificadas formas de aprender. Isso também justifica o esforço depreendido na construção de uma prática educativa inovadora, na constituição do currículo ciborgue para a formação inicial docente.

É importante ressaltar que o objetivo deste artigo consiste em analisar uma experiência de ciborguização de um curso de formação de professoras/es. Nos limites desse propósito, o trabalho não aprofunda a discussão em torno de críticas ao uso de tecnologias, por partir de uma escolha teórica que compreende a presença delas nos currículos como um imperativo. Tal abordagem teórica não tem como propósito colocar em questão a utilização das tecnologias no ensino, mas abordá-la como exigência, conduzindo os comportamentos na sociedade contemporânea. De acordo com essa perspectiva, a presença intensiva e extensiva das tecnologias digitais nas múltiplas dimensões da vida exige alterações nas formas de ensinar e aprender. Com isso, o artigo apresentado pretende compreender os possíveis efeitos de práticas curriculares ciborguizadas, não adentrando em outras discussões.

\section{INOVAÇÃo E FORMAÇÃo INICIAL DE PROFESSORES}

Entende-se neste texto a noção de inovação como "um processo que provoca uma ruptura, mesmo que parcial e temporária" (VEIGA, 2000, p.175). A experiência aqui relatada se caracteriza como inovadora ao buscar romper com o tradicional modo de ensinar e aprender na formação inicial de professores/as da educação básica. Isso porque, de acordo com Gatti (2014), os cursos de formação de professores/as no Brasil, de modo geral, possuem um modelo petrificado no século XX, que tem dificuldade em inovar por, ainda, estar arraigado na concepção de ciência do século XIX.

Para que a inovação aconteça é importante romper com o modelo posto no cenário atual, proporcionando que o/a futuro/a professor/a vivencie na sua formação inicial práticas educativas inovadoras. Isso porque em sua prática profissional, a/o docente lidará com estudantes do ensino básico que já têm suas formas de aprender alteradas pelas tecnologias digitais. Essas/es ciborgues demandam outros processos de ensino que incorporem as tecnologias digitais. Desse modo, é difícil para o/a futuro/a professor/a "com base apenas na experiência profissional, construir critérios de análise e uso das tecnologias no processo de ensino-aprendizagem" (CARLINI, 2008, p. 88), sem ter tido a oportunidade de se apropriar 
das tecnologias ao longo de sua formação acadêmica. Por isso, entendemos que a partir da incorporação das tecnologias no processo de ensino-aprendizagem na formação de licenciados/as, esses/as futuros/as profissionais se tornarão usuários/as e avaliadores/as dos recursos tecnológicos (CARLINI, 2008).

Considerando que a prática educativa se sustenta na "combinação entre reprodução do que realiza em sua atuação profissional específica; as experiências pregressas, vividas enquanto aluno; e aquilo que vem sendo sedimentado por meio da própria atuação enquanto professor" (ALMEIDA; PIMENTA, 2011, p. 8), a inovação assume um caráter de processo que urge nos sistemas educacionais com o objetivo de romper com essa reprodução da prática de ensino. Nesse sentido, se em nenhum dos pontos desse tripé houver uma ruptura paradigmática, há tendência dos/as docentes continuarem reproduzindo processos de ensino-aprendizagem tradicionais, sustentando currículos petrificados que não acompanham as mudanças sociais, políticas, tecnológicas e econômicas e as demandas da geração de estudantes ciborgues.

Assim, a experiência aqui relatada possui uma dimensão inovadora à medida que atribui valor à imbricada relação entre tecnologias e currículo do curso de licenciatura, transgredindo o modelo tradicional de ensino, em busca de ciborguizar o currículo da Pedagogia. Gatti (2014) ao construir um panorama da formação inicial de professoras/es nas licenciaturas afirma que o cenário precisa ser enfrentado. A autora argumenta que no

foco das licenciaturas, esse enfrentamento não poderá ser feito apenas em nível de decretos e normas, o que também é importante, mas é processo que deve ser feito também no cotidiano da vida universitária. Para isso, é necessário poder superar conceitos arraigados e hábitos perpetuados secularmente e ter condições de inovar. Aqui, a criatividade das instituições, dos gestores e professores do ensino superior está sendo desafiada (GATTI, 2014, p.36).

Nesse sentido, a inovação na prática de ensino não inclui apenas novidades na forma de ensinar e aprender. Vai além, apresentando uma ruptura de paradigmas. Há uma reorganização da teoria e da prática educativa, em que se busca articulá-las por meio das tecnologias. Nas experiências curriculares aqui sistematizadas, as/os futuras/os professoras/es vivenciam práticas ciborgues já em sua formação inicial, para que se apropriem delas e possam utilizá-las em suas futuras práticas de ensino.

Para Cunha (2008, p. 29), o processo de inovação se inicia com a reflexão sobre a prática educativa e "incluir a dúvida e a insegurança como parte do processo de decisão profissional significa um importante avanço dos professores na direção de uma ruptura paradigmática". Sendo assim, a experiência aqui relatada emerge de algumas dúvidas e inquietações. Primeiro em relação à formação de licenciadas/os que, geralmente, têm pouco ou nenhuma vivência com as tecnologias digitais nos currículos dos cursos de graduação. Segundo, que essas/es futuras/os profissionais lidarão com jovens que possuem íntima relação com as tecnologias e precisam, portanto, estar devidamente formadas/os para isso.

n. 1


Para Masetto (2015), a inovação trata-se de um conceito amplo e multidimensional, a qual é provocada por mudanças na sociedade e por reflexões que estão perpassando as universidades. Masetto (2015) apresenta alguns indicadores de inovação no ensino superior, presentes na experiência educativa aqui relatada. Um desses indicadores refere-se às novas organizações curriculares que, nesta proposta, apresenta-se como a possibilidade de constituição de um currículo ciborgue. Masetto (2015) propõe também como indicador de um currículo inovador, a inserção das tecnologias nos processos de ensino-aprendizagem.

Partindo dessa noção de inovação, argumentamos que a experiência aqui relatada rompe com a ideia de domesticação das tecnologias digitais e dos saberes tecnológicos em função somente dos objetivos educacionais e das propostas didático-metodológicas. Esse tipo de prática pode acarretar um uso descontextualizado e forçado das tecnologias, em que se corre o risco do modismo tecnológico-educacional. Em vez disso, esta experiência educativa busca transgredir com esse modelo ao fundir currículo e tecnologias digitais, estabelecendo uma íntima conexão, uma composição entre esses artefatos culturais. O currículo está a serviço da tecnologia e a tecnologia a serviço do currículo, em dupla direção, em que as potencialidades tecnológicas são utilizadas a favor da educação, ao mesmo tempo em que os saberes educacionais potencializam as tecnologias. Esse cenário demanda dos sujeitos pedagógicos outras posições nos processos educativos. Assim, é requerido do/a professor/a, a função de mediador/a do processo de ensino-aprendizagem e o/a estudante é instigado/a a participar ativamente e se envolver nas atividades propostas. São vários os efeitos dessa ciborguização curricular, alguns já conhecidos e outros ainda por serem investigados. Dentre eles, a produção de diferentes subjetividades tanto das/os docentes quanto das/os estudantes.

Muitos dos efeitos das inovações educativas são indeterminados "isso porque os efeitos de uma inovação são mais ou menos difusos, em razão de que repercutem para além do fenômeno e que ela intervém diretamente" (VEIGA, 2000, p.175). Com isso, abrem-se possibilidades de ciborguizar a formação docente, atingindo a prática educativa dos/as futuros/as professores/as que certamente trabalharão com jovens ciborgues no exercício da docência na educação básica. Nesse processo, há a possibilidade de fabricar outros sujeitos pedagógicos, outras formas de ensinar e aprender e outras relações de poder-saber.

Antes de apresentar a metodologia de ensino-aprendizagem que favoreceu a ciborguização do currículo da formação inicial de professores, abordamos o contexto da disciplina em que a inovação foi proposta, com o intuito de mostrar que ela se realizou em determinado contexto histórico social e que as ações implementadas buscam romper com estrutura paradigmática existente. 


\section{CONTEXTO DA PRÁtiCA EDUCATIVA}

O uso das Tecnologias de Informação e Comunicação (TICs) nas práticas pedagógicas com os/as jovens estimula o envolvimento delas/es com a escola e com os/as próprios/as jovens (DAYRELL, 2009). Nesse contexto, merece destaque o uso da internet nas esferas de sociabilidade juvenil, a qual é marcada pela participação dos/as jovens em sites de relacionamentos, blogs e ferramentas de redes sociais. A esse respeito, Dayrell (2009, p.7) afirma que diante da popularidade das mídias eletrônicas e tecnologias digitais, acredita-se que essas "manifestações culturais juvenis podem e devem ser utilizadas como ferramentas que possam facilitar a interlocução e o diálogo entre os/as jovens e a escola, contribuindo assim para o desenvolvimento de práticas pedagógicas inovadoras".

A juventude contemporânea está imersa em diferentes culturas que afloram à medida que entram em contato com as múltiplas possibilidades da internet. Segundo Garbin (2009), essa juventude ouve músicas nos diversificados aparelhos eletrônicos que oferecem essa possibilidade, ao mesmo tempo que posta fotos, assiste aos vídeos, faz comentários e utiliza as ferramentas de rede social. De acordo com a autora, a internet possibilita a produção de novos conhecimentos, comunicação e lazer e a informação simultânea. A juventude está, portanto, cada vez mais ciborguizada e demanda currículos que estejam em consonância com essa sua forma de existir (SALES, 2010). Além disso, como bem destacam Mendes, Souza Neto e Reis (2012, p. 258):

a incorporação das tecnologias no currículo da educação básica pode ser compreendida como uma das condições necessárias para o exercício da cidadania, pois a inclusão digital precisa ser assimilada também como parte do processo de inclusão social, cultural, tecnológica e intelectual, favorecendo assim, a efetiva participação dos sujeitos na cultura.

Nesse contexto de imperativo da ciborguização curricular, o plano de curso da disciplina Teorias de Currículo, do curso de Pedagogia, foi elaborado incorporando as tecnologias digitais. A proposta de trabalho mescla estratégias curriculares em que as tecnologias digitais são centralmente utilizadas, com outras práticas em que elas não são as protagonistas das cenas curriculares. Esse trabalho foi desenvolvido no curso, com carga horária semestral de 60h/a, ministrada no curso de graduação em Pedagogia, durante os dois semestres letivos de 2014. Em cada semestre a proposta aqui apresentada foi desenvolvida com duas turmas do quarto período do curso, envolvendo um total de 150 alunas/os no ano.

É importante destacar que esse trabalho no âmbito do ensino, junto às turmas de graduação em Pedagogia, articula-se a um projeto de pesquisa, cujo objetivo geral é analisar o funcionamento do currículo ciborgue de uma escola pública estadual de Ensino Médio. Com esta investigação, pretendeu-se mapear e divulgar a produção acadêmica acerca da ciborguização curricular, localizando as escolas estaduais de Ensino Médio que a praticam e

\begin{tabular}{|l|l|l|l|l|l|} 
(C) Rev. Inter. Educ. Sup. & Campinas, SP & v.4 & n.1 & p.6-24 & jan./abr. 2018 \\
\hline
\end{tabular}


discutir os efeitos do currículo ciborgue. O que interessou saber é como se dá o processo de ciborguização e os seus efeitos na produção de subjetividades juvenis. Buscou-se compreender o funcionamento do currículo ciborgue nessas escolas, suas estratégias, seus efeitos e que tipo de jovem demanda. Foi investigado o currículo, a proposta do Ensino Médio e sua relação com realidade do/a aluno/a e as demandas postas pelos/as jovens ciborgues.

O trabalho aqui apresentado articula-se ainda ao projeto de extensão universitária: Portal EMdiálogo $^{2}$, o qual é uma iniciativa do Observatório Jovem da Universidade Federal Fluminense - UFF - e Observatório da Juventude da Universidade Federal de Minas Gerais UFMG. O projeto contou com o apoio da Secretaria de Educação Básica do Ministério da Educação - MEC. A proposta do site é estimular e contribuir para o diálogo entre todas/os as/os interessados na melhoria das condições de oferta da escola pública de Ensino Médio no Brasil, buscando incentivar os jovens e as jovens estudantes a serem protagonistas do site, participarem das discussões de forma crítica e interativa e além disto possibilitar que suas demandas, reivindicações e sugestões sejam ouvidas. O Portal EMdiálogo oferece possibilidades para alterar as práticas curriculares no Ensino Médio, na medida em que opera com elementos característicos da cultura juvenil, especialmente da cibercultura. O objetivo é estimular mais e melhores diálogos nas escolas e também abrir espaços para que as boas práticas já existentes circulem e que surjam novas experiências de conversação, entendimento e busca de soluções para os graves problemas encontrados nas escolas de Ensino Médio público no Brasil ${ }^{3}$.

O trabalho de produção de um currículo ciborgue para a formação docente, aqui apresentado, articula, portanto, as atividades de ensino, pesquisa e extensão desenvolvidas na universidade. A seguir, apresentamos como se deu o processo de ciborguização do currículo do curso de licenciatura em Pedagogia.

\section{PRÁtICA DE ENSINO-APRENDIZAGEM INOVADORA: CIBORGUIZANDO O CURRÍCULO}

Entendemos que o/a professor/a é criador/a "de situações de aprendizagem portadoras de sentido e de regulação" (PERRENOUD, 1999, p.18). Toda sequência didática desenvolvida na disciplina persegue essa compreensão. Assim, o primeiro procedimento adotado é um mapeamento das formas de aprender das/os alunas/os da Pedagogia. Isso é feito por meio de

\footnotetext{
${ }^{2}$ Disponível em: 〈www.emdialogo.uff.br〉.

${ }^{3}$ Mais informações sobre o projeto Portal EMdiálogo encontram-se sistematizadas nas seguintes publicações: Sales; Ferreira; Vargas (2015); Ferreira; Vargas; Sales (2015); Sales et al. (2014); Oliveira (2014); Oliveira; Said; Sales (2013).

\begin{tabular}{|l|l|l|l|l|l|}
\hline (C) Rev. Inter. Educ. Sup. & Campinas, SP & v.4 & n.1 & p.6-24 & jan./abr. 2018 \\
\hline
\end{tabular}
}


um questionário, elaborado no Google Drive e publicado no blog da professora ${ }^{4}$ na aba de cada turma. Essa ferramenta é bastante apropriada, já que o próprio Drive tabula os resultados do questionário, gerando gráficos que permitem uma análise do perfil da turma, bem como da diversidade de formas de aprender. Entende-se que é de extrema importância conhecer as/os estudantes para adequar as estratégias de ensino-aprendizagem a elas/es, bem como os recursos a serem utilizados mediante o perfil traçado. Esse procedimento simples rompe com as práticas cotidianas das salas de aulas universitárias. Isso porque, de acordo com Pimenta e Anastasiou (2010, p. 228), as/os professoras/es universitárias/os encontram nas salas de aulas alunas/os diferentes do que, possivelmente, esperavam encontrar e "muitas vezes as características reais desses jovens não são objeto de preocupação por parte do professor".

Como muitas das respostas a esse questionário incluem a realização de resumos e também anotações de aula, como formas prevalentes para que a aprendizagem aconteça, são sugeridas às/aos estudantes duas práticas a serem desenvolvidas ao longo do semestre. A primeira delas consiste na elaboração de uma síntese dos textos de leitura obrigatória e sua publicação no grupo da turma do Facebook, antes de cada aula. A segunda prática consiste em compartilhar no mesmo grupo, as notas de aula, realizadas durante cada uma delas. As/os alunas/os se revezam nessas atividades de registro e compartilhamento. Sendo assim, trabalha-se com a perspectiva do ensino híbrido, denominado também de blended learning, o qual é caracterizado pela associação entre aulas presenciais e atividades que utilizam as tecnologias digitais, neste caso o Facebook . De acordo com Freitas, Mendes e Miranda (2012), o modelo híbrido possibilita maior participação das/os estudantes, tendo em vista que há uma tendência de diminuição da timidez nas atividades mediadas por computador. Feito esse acordo inicial, as aulas são desenvolvidas de modo a alternar práticas em que as tecnologias são intensamente utilizadas, com outras mais tradicionais de ensino, de modo a diversificar as estratégias curriculares e com isso contemplar o maior número possível de formas de aprendizagem.

A ementa da disciplina desenvolvida é: Teorias do currículo: diferentes conceitos e perspectivas. Dimensões histórica, política, social e cultural do currículo. Questões normativas e legais na definição do currículo. Seleção de conteúdos e formas de organização do currículo. O processo de elaboração de currículos: relações de poder, conflitos, disputas e alianças. Para trabalhar esses tópicos, por vezes e de modo alternado, são utilizadas aulas dialogadas, em que os aspectos conceituais dos textos base são desenvolvidos. Nessas aulas utiliza-se o Prezi ${ }^{5}$ como ferramenta de apresentação e também a exibição de pequenos vídeos para suscitar análises, com base no conteúdo estudado. Intercalando com essas aulas dialogadas, são desenvolvidas as atividades ciborguizadas. São elas: a elaboração de um

4 Disponível em: <https://professorashirleisales.wordpress.com>.

${ }^{5}$ O Prezi.com é um software on-line que permite a criação de apresentações não lineares, por meio do conceito de apresentações de zoom. Uma alternativa bem mais interessante do que o Power Point.

\begin{tabular}{l|l|l|l|l|l} 
(C) Rev. Inter. Educ. Sup. & Campinas, SP & v.4 & n.1 & p.6-24 & jan./abr. 2018 \\
\hline
\end{tabular}


Mapa conceitual, com a utilização do Xmind ${ }^{6}$; o debate das concepções curriculares de Paulo Freire e Dermeval Saviani no Facebook; a preparação e publicação no blog ${ }^{7}$ de uma web aula; uma prova individual no Facebook.

O mapa conceitual é proposto como atividade avaliativa de sistematização e organização dos conceitos estudados. A ideia é dispor de modo esquemático os conceitos de cada teoria de currículo: tradicional, crítica e pós-crítica, constitutivas do campo curricular. A ferramenta utilizada é o Xmind que proporciona uma disposição dos conceitos estudados, em sua respectiva vertente teórica. Os mapas conceituais proporcionam a organização dos conceitos chaves e destacam visualmente aqueles mais importantes dos secundários ou específicos. De acordo com Moreira (1997, p. 08), os mapas conceituais têm potencial para realizar profunda transformação no processo de ensino-aprendizagem e de avaliação, isso porque "procuram promover a aprendizagem significativa e entram em choque com técnicas voltadas para aprendizagem mecânica". Com essa prática, muda-se também a forma de avaliar porque o/a professor/a procura "interpretar a informação dada pelo aluno no mapa a fim de obter evidências de aprendizagem significativa" (MOREIRA, 1997, p.08). Essa atividade favoreceu a construção do conhecimento das/os alunas/os acerca da organização do campo curricular, suas vertentes teóricas e respectivos conceitos. Foi notório que a produção coletiva do mapa possibilitou uma visualização do campo e facilitou o entendimento de sua composição por parte das/os estudantes.

A segunda prática ciborgue, o debate no Facebook, é realizada utilizando todos os recursos dessa rede social digital. A preparação para ele é feita por meio da leitura prévia de textos que discutem as concepções curriculares da Pedagogia do Oprimido e a Pedagogia Crítico Social dos Conteúdos ${ }^{8}$. A aula acontece toda no ciberespaço. No laboratório de informática da faculdade, a turma é dividida ao meio. Uma parte cria um fake de Paulo Freire, a outra de Dermeval Saviani. Para cada perfil, há um login e senha que são compartilhados pelo respectivo grupo (metade da turma). Ou seja, cada grupo fica logado em um perfil único. Para a construção dos perfis, devem pesquisar na internet aspectos gerais sobre a vida e obra dos respectivos autores e publicar. Feito isso, os dois perfis se adicionam mutuamente como amigos do Facebook e a professora também. Então o debate acontece todo no Facebook. A professora fica teclando com a turma toda, simultaneamente. Isso exige de todas/os destreza, capacidade de análise, questionamento e argumentação.

A proposta é que o debate seja respeitoso. Isso, no entanto, não exclui a zuação, o lúdico e o jocoso, marcas bastante características do Facebook. A orientação é pra que as/os alunas/os conversem na timeline de cada perfil criado, de modo que a docente possa ver as interações e participar delas. No entanto, muitas vezes as/os alunas/os passam para a comunicação in box,

\footnotetext{
${ }^{6}$ Xmind é um software para a construção de fluxograma no formato de mapas mentais.

${ }^{7}$ Disponível em: <https://professorashirleisales.wordpress.com>.

${ }^{8}$ Silva (1999); Menger (2012); Menezes; Santiago (2014).

() Rev. Inter. Educ. Sup. $\quad$ Campinas, SP $\quad$ v.4
}


o que impede a intervenção da professora no debate. Essa atividade também contribuiu para a construção do conhecimento pelas/os alunas/os que, em sua maioria, demonstraram ter compreendido os principais argumentos dos autores estudados. Para conseguir postar e participar do debate, as/os estudantes precisaram pesquisar as teses dos teóricos e utilizá-las durante a aula.

A terceira prática ciborgue é a elaboração e publicação da web aula. Essa atividade é avaliativa e realizada em grupo. A proposta é desenvolver uma vídeoaula dirigida à professoras/es da educação básica, acerca do tema do respectivo grupo. São sete os temas contemplados: Currículo e gênero; Currículo e sexualidade; Currículo e classes sociais; Currículo e culturas do campo e da cidade; Currículo e cultura negra; Currículo e culturas indígenas; Currículo e cibercultura.

São sugeridas várias leituras preparatórias e as/os alunas/os são orientadas/os a elaborarem um plano da aula e um roteiro da gravação do vídeo. Elas/es são estimuladas/os a utilizar todo e qualquer recurso e ferramenta que julgarem interessantes. A vídeoaula deve ter duração entre 7 e 10 minutos. Depois de pronta, devem fazer o upload para o YouTube. Em seguida, o vídeo deve ser publicado no blog, na aba da disciplina Teorias de Currículo de sua respectiva turma. É preciso elaborar um parágrafo que apresente a proposta da vídeoaula, o qual também deve ser postado. Esse exercício é totalmente autoral e desenvolve ainda outra dimensão importante na formação de professoras/es: o trabalho colaborativo, em equipe.

Para além do trabalho colaborativo, as/os futuras/os professoras/es desenvolvem competências e habilidades para o exercício da docência. Elas/es preparam o objeto de aprendizagem, a vídeoaula. Para isso precisam estudar o tema, conhecer e/ou pesquisar determinadas tecnologias e planejar a aula. Nesse sentido, "não se trata apenas de uma formação no conhecimento e no uso dos recursos (formação em informática, uso da rede, etc.), mas nas possibilidades didáticas e formativas das novas tecnologias" (ZABALZA, 2004, p. 173). De acordo com Zabalza (2004, p.173), esse é o desafio das novas tecnologias e a formação de professores de não "fazer a mesma coisa que se fazia antes com meios mais sofisticados".

Por fim, a última atividade ciborgue é a prova no Facebook. Ela consiste em analisar a publicação de uma prática curricular que tenha sido divulgada na mídia. Essa publicação é selecionada de modo a suscitar a discussão sobre práticas curriculares inovadoras implementadas em escolas brasileiras, especialmente as públicas. Essa publicação é postada na timeline da professora. A turma é orientada a analisá-la, com base nos conceitos estudados. Essa análise consiste na sistematização do conteúdo trabalhado ao longo da disciplina e deve ser publicada como comentário na timeline. A proposta consiste em compartilhar em uma poderosa Rede Social, como o Facebook, as reflexões acerca do conteúdo estudado. As/os alunas/os que não quiserem publicar suas respostas podem fazer a prova manuscrita, ou

\begin{tabular}{l|l|l|l|l|l} 
(C) Rev. Inter. Educ. Sup. & Campinas, SP & v.4 & n.1 & p.6-24 & jan./abr. 2018 \\
\hline
\end{tabular}


enviar por e-mail. A prova ainda permite a ampla consulta às anotações de aula e também ao conteúdo disponível na internet. Com isso, as sistematizações ficam públicas e acessíveis a um incontável número de pessoas. A correção, no entanto, é enviada de modo privado, in box, para cada aluna/o, a fim de não suscitar qualquer tipo de constrangimento. Enfim, a busca de ciborguizar o currículo de formação de professoras/es tem por objetivo unir cada vez mais o contexto tecnológico aos processos de ensino-aprendizagem.

\section{AVALIAÇÃO DO PROCESSO DE APRENDIZAGEM DOS/AS ESTUDANTES}

Entendemos que a avaliação do processo de aprendizagem desenvolvida na disciplina de Teorias de Currículo possui um caráter formativo e processual. Isso porque se utilizam diferentes estratégias e ferramentas, reconhecendo a heterogeneidade dos/as estudantes. Dessa forma, avaliam-se todas as atividades propostas, inclusive o mapa conceitual, a prova e a vídeoaula de forma igualitária, o que reflete na distribuição de pontos, em que o valor é dividido de forma equânime. Busca-se associar os processos de ensino-aprendizagem e da avaliação, entendendo que a avaliação formativa apresenta-se imbricada nas interações didáticas (PERRENOUD, 1999).

A autoavaliação é o momento em que a professora compartilha com a turma a tarefa avaliativa. As/os alunas/os precisam avaliar o trabalho que elas/os desenvolveram, o compromisso, a responsabilidade e a dedicação delas/os para que a aprendizagem acontecesse. Assim, solicitou-se às/aos estudantes que avaliassem, por escrito, o uso das tecnologias digitais durante o desenvolvimento da disciplina Teorias de Currículo. De modo geral, e prevalentemente, elas/es registraram que o trabalho desenvolvido foi bastante acertado, produziu motivação e favoreceu os processos de aprendizagem. Alguns exemplos dessas análises podem ser vistos nas seguintes respostas: "A sua aula de Paulo Freire e Dermeval Saviani foi sensacional! E como foi fácil aprender dessa forma, teve conceitos que tivemos duvidas e no momento foi esclarecidas, teve um momento de disputa, porém saudável!"; "Eu nunca tive essa experiência antes e acredito que foram muito eficazes e auxiliaram no meu entendimento sobre a matéria." "O uso das diferentes tecnologias despertou o interesse nos temas abordados, descontração da aula e ainda um bom aproveitamento do tempo. Proporcionaram momentos de muita aprendizagem, de trocas e sensibilização. Promoveram ainda o despertar para as várias possibilidades de se ensinar, atentando para o papel do professor como um mediador, que instiga os alunos para busca do conhecimento. Foram aulas que trouxeram prazer e motivação para ir além do que está pronto, a busca pelo novo pela inovação! Gostei demais das aulas”

Pontuaram ainda como se sentiram desafiadas/os pelas inovações propostas no curso: "lembrei da questão de causar um desequilíbrio, de tirar a pessoa da zona de conforto. Acho que é isso, você causa um desequilíbrio e nos faz ir em busca do novo. Além de nos dar uma

\begin{tabular}{l|l|l|l|l|l}
\hline (c) Rev. Inter. Educ. Sup. & Campinas, SP & v.4 & n.1 & p.6-24 & jan./abr. 2018 \\
\hline
\end{tabular}


certa autonomia. E pensando na web aula (porque foi assim que você me desequilibrou, já que eu construí um vídeo pela primeira vez) é sempre bom ir de encontro ao novo. Principalmente para a nossa profissão, que como você mesma diz, deve sempre se atualizar, inovar, renovar. Ou seja, acho ótimo esse uso de tecnologias"; "Embora tenha sido desafiadora a elaboração da web aula, foi uma proposta de trabalho que mexeu com nossas expectativas e com o nosso comodismo, fazendo toda a turma se empenhar e buscar coisas novas"; "a proposta da web aula, que foi a coisa mais inovadora que fizemos nesse curso até hoje (rsrs), fazendo aulas no facebook, principalmente esta prova, que desafia a gente a olhar para esta ferramenta de uma outra forma, não só para lazer e comunicação em geral, mas também como um ambiente de construção de aprendizagem, isso foi genial!"

Descreveram também como as práticas desenvolvidas melhoraram a relação professor/aaluna/o: "Acho importante também salientar que a utilização das tecnologias traz ao aluno uma autonomia muito grande, já que estes podem estar conectados em várias "coisas" ao mesmo tempo. Isso produz uma sensação de confiança do professor para com o aluno e viceversa e isso também torna o ensino-aprendizagem mais prazeroso e estimulante."

Além disso, concluíram que se sentiram estimuladas/os a utilizar os recursos tecnológicos em suas atividades profissionais como futuras/os professoras/es "Usar tecnologias na aula me fez desejar aprender mais, me fez desejar refletir sobre tudo que faço com meus alunos."; "sua metodologia é inovadora que resulta de forma positiva na formação dos alunos. Pelo menos para mim, houve um aprendizado diferenciado e mais significativo em comparação as matérias que já fiz durante o curso. Me abriu possibilidade para novos horizontes ao uso destas ferramentas em sala de aula. Na educação, inovar é preciso para tentar resgatar e despertar o interesse das crianças nas escolas. Você mostrou que o uso da internet, não precisa ser um problema dentro de sala, e as vezes a solução, como apoio didático nas aulas."; "As tecnologias digitais são elementos necessários para que a nossa formação como pedagogas e educadoras seja ampliada, para que possamos trabalhar com a criatividade e diversas possibilidades, propondo novas atividades para os alunos, bem como foi assim proposto para a turma."; "Vivi uma experiência muito legal, gosto de tecnologia e as aulas me prenderam. Aprendi muito com a utilização dos recursos digitais e espero que exercendo a docência eu consiga envolver meus alunos e propiciar experiências diferenciadas e atrativas de aprendizado através do uso das mais diversas ferramentas como esta."

No entanto, algumas/alguns alunas/os também pontuaram os problemas e desafios enfrentados ao longo dos trabalhos desenvolvidos: "Para alunos mais velhos, conservadores, pode representar um entrave a realização de atividades. Por outro lado, para os mais jovens, pode significar dispersão."; "Porém, na aula de Paulo Freire e Saviani, eu fiquei um pouco perdida" "Obviamente, para alguns menos habituados com essas tecnologias, foi um pouco mais complicada a utilização, mas sem dúvidas foi uma oportunidade de se familiarizar e de certa forma entender que no mundo tão conectado em que vivemos, não dá mais para

\begin{tabular}{|l|l|l|l|l|l} 
(C) Rev. Inter. Educ. Sup. & Campinas, SP & v.4 & n.1 & p.6-24 & jan./abr. 2018 \\
\hline
\end{tabular}


querermos uma escola "offline""; "Avalio como sendo boas apesar das dificuldades que encontrei no primeiro momento, mas acho que faz parte quando nos deparamos com algo novo, me senti um pouco impotente diante dessa novidade."

\section{AUtoAVAliaÇÃo da PRofessora formadora}

De modo geral, e prevalentemente, era bastante gratificante perceber que as/os alunas/os estavam aprendendo e que estavam motivadas a isso. Todo o entusiasmo da maioria delas/es era um fator potencializador para a docente. A alegria e euforia eram predominantes durante as aulas. As reações positivas das/os alunas/os diante da surpresa e ineditismo das práticas é algo extremamente recompensante e que motiva como professora. Constatar o brilho nos olhos de quem aprende, com prazer e encantamento é uma experiência única e que justifica todo esforço empreendido na construção de um currículo ciborgue na formação de professoras/es.

Foi bastante significativo experimentar concretamente as potencialidades da ciborguização curricular e os efeitos positivos observados tanto na motivação das/os alunas/os para a realização das atividades, quanto na efetiva aprendizagem construída. Tudo isso gerou ainda o sentimento de que estava se desenvolvendo um trabalho formativo consistente e de relevância social. Tais sensações são extremamente gratificantes e fortalecem profissionalmente.

\section{CONSIDERAÇõES FINAIS}

Consideramos que é urgente a incorporação das tecnologias digitais nos cursos de formação docente, de modo a promover uma compreensão mais consistente sobre o sentido do uso das tecnologias, colaborando para a inovação nas práticas curriculares. Esse desafio deve ser enfrentado pelas instituições encarregadas dessa formação, de modo institucional e com projetos coletivos, e não apenas com ações isoladas, baseadas na ousadia de algumas/alguns professoras/es. Agir de modo individual foi um exercício profissional um tanto solitário, que por vezes deixou dúvidas acerca do melhor caminho a trilhar. Pensamos que um projeto institucional poderia dar mais consistência e subsídios para o efetivo desenvolvimento das práticas curriculares ciborgues aqui sistematizadas.

Além disso, é preciso pontuar que mesmo em uma instituição importante, já consolidada, como a Universidade Federal de Minas Gerais, há inúmeras dificuldades para o uso das tecnologias durante as aulas. Desde as mais básicas como falta de funcionária/o para abrir ou fechar o laboratório de informática, até equipamentos que não funcionam, internet que cai, energia elétrica que acaba repentinamente etc. Isso exige, portanto, de nós professoras/es formadoras/es, ter sempre um plano B para equacionar esses inúmeros problemas, e também 
para atender às/aos alunas/os que se recusam a usar as tecnologias. Seja por não saberem utilizar, ou por não aprovarem o seu uso em sala de aula. Isso tudo demandou extrema paciência, bom humor, perspicácia, delicadeza e uma escuta super atenta, a fim de identificar os problemas que iam surgindo, assim como de criar soluções para eles. Em algumas situações, as/os alunas/os pareciam inseguras/os com as novas práticas. Não tinham confiança de que aquilo que estava acontecendo era uma aula de fato e de que elas/es poderiam aprender de verdade. Por vezes, o processo foi bastante cansativo, desgastante, exigindo grande capacidade de argumentação, negociação e convencimento do grupo.

Outro aspecto extremamente importante a ser considerado é que inúmeras vezes houve insegurança e tensão no desenvolvimento das práticas ciborgues. Afinal, a professora não domina totalmente o uso das tecnologias digitais. Isso por vezes fragilizava a própria autoconfiança como professora. Havia medo de não saber exatamente como proceder, já que por mais que houvesse um grande esforço em cercar o planejamento das aulas, elaborando inclusive propostas alternativas para as eventualidades imaginadas, sempre acontecia algo que obviamente não havia sido previsto. Essas sensações ensinaram na prática o que a teoria insiste em argumentar: a relação professor/a-aluna/o é necessariamente uma relação horizontal de aprendizagem mútua. Além disso, construiu-se a certeza de as práticas adotadas na disciplina eram de fato inovadoras porque os sentimentos de insegurança e dúvidas fizeram parte do processo e demandou invenções, criações, ousadia, transgressões e coragem, além do respeito e a honestidade na condução das aulas. Tais elementos foram imprescindíveis e viabilizaram a ciborguização do currículo de formação docente.

De todo modo, e como balanço final, concluímos que os trabalhos desenvolvidos foram bastante exitosos e inovadores, porque atingiram os objetivos de ciborguizar a formação docente, de contemplar os diferentes modos de aprender e de incentivar as/os futuras/os professoras/es a utilizar diferentes estratégias curriculares, com variados recursos tecnológicos, em sua atuação docente. Por tudo isso, avaliamos que a experiência aqui relatada obteve resultados bastante satisfatórios, o que nos motiva a compartilhá-la e a continuar pesquisando modos de aprimorá-la permanentemente.

\section{REFERÊNCIAS}

ALMEIDA, Maria Isabel de; PIMENTA, Selma Garrido. Pedagogia universitária: caminhos para a formação de professores. São Paulo: Cortez, 2011.

CARLINI, Alda Luiza. O professor do ensino superior e a inclusão digital. In: CARLINI, Alda Luiza; SCARPATO, Marta (Org.). Ensino Superior: questões sobre a formação do professor. São Paulo: Avercamp, 2008. 
CUNHA, Maria Isabel. Inovações pedagógicas: o desafio da reconfiguração de saberes na docência universitária. Cadernos pedagogia universitária. São Paulo: USP, 2008.

DAYRELL, Juarez. Uma diversidade de sujeitos. O aluno do Ensino Médio: o jovem desconhecido. Salto para o futuro, Brasília, v19, boletim 18, p. 16-23, nov. 2009. (Juventude e escolarização: os sentidos do Ensino Médio). Disponível em: < http://portaldoprofessor.mec.gov.br/storage/materiais/0000012176.pdf > Acesso em: 02 mai. 2015.

FREITAS, Christiana Soares de; MENDES, Nilda; MIRANDA, Cecília. In: ALFINITO, Solange; PASCHOAL, Alexandre Maduro-Abreu; CANTAL, Clara Brasiliana Ribeiro. Aplicações e tendências do uso de tecnologias de informação e comunicação na educação superior presencial no Brasil. Brasília: Universidade de Brasília, Departamento de Administração da Faculdade de Economia, Administração e Contabilidade, 2012.

GATTI, Bernadete A. A formação inicial de professores para a educação básica: as licenciaturas. Revista USP, São Paulo. n.100, p.33-46, dez./fev. 2013-2014.

GARBIN, Maria Elisabete. Participação juvenil nas escolas. Conectados por um fio: alguns apontamentos sobre internet, culturas juvenis contemporâneas e escola. Salto para o futuro, Brasília. v.19, boletim 18, p.30-40, nov, 2009. (Juventude e escolarização: os sentidos do Ensino Médio). Disponível em: < http://portaldoprofessor.mec.gov.br/storage/ materiais/0000012176.pdf > Acesso em: 02 mai. 2015.

GREEN, Bill; BIGUM, Chris. Alienígenas na sala de aula. In: SILVA, Tomaz Tadeu da. (Org.). Alienígenas na sala de aula: uma introdução aos estudos culturais em educação. 5. ed. Petrópolis: Vozes, 2003, p. 208-43.

FERREIRA, Aline Gonçalves; VARGAS, Francielle Alves; SALES, Shirlei Rezende. Relações de gênero e sexualidades no ciberespaço. In: RAMOS, Tânia Regina Oliveira; ZANDONÁ, Jair; DUARTE, Cláudia Renata; TELÉSFORO, Júlia. (Org.). Imagens e memória: um livro pôster. Fazendo gênero 10. 1ed.Tubarão: Copiart, 2015. p. 192-193.

LEAL, Rafaela Esteves Godinho. Dispositivo de inovação no ensino superior: produção do docentis innovatus e do discipulus iacto. 2017. Dissertação (Mestrado) - Universidade Federal de Minas Gerais, Belo Horizonte, 2017.

MASETTO, Marcos. Formação de professores para currículos inovadores no ensino superior: um estudo num curso de Direito. E-curriculum, São Paulo, v.13, n.1, p.5- 27, jan./mar. 2015.

MENDES, Geovana Mendonça Lunardi; SOUZA NETO, Alaim; REIS, Valdeci. As experiências de professores e alunos com o uso do laptop em escolas públicas do sul do Brasil: inovações curriculares e aprendizagem colaborativa. Visão Global, Joaçaba, v. 15, n. 1-2, p. 257-268, jan./dez. 2012. 
MENEZES, Marília Gabriela de; SANTIAGO, Maria Eliete. Contribuição do pensamento de Paulo Freire para o paradigma curricular crítico-emancipatório. Pro-Posições, Campinas, v. 25, n. 3 (75), p. 45-62, set./dez. 2014. Disponível em: < http://www.scielo.br/scielo. php?script=sci issuetoc $\&$ pid=0103-730720140003\&lng=en $\& n r m=i s o>$. Acesso em: 02 mai. 2015.

MENGER, Amanda da Silva; VALENÇA, Vera Lúcia Chacon. A Pedagogia HistóricoCrítica no Contexto das Teorias de Educação. Poiésis, v. 6, n. 10, p. 497 - 523, jul./dez. 2012.

MOREIRA, Marco Antônio. Mapas conceituais e aprendizagem significativa. 1997. Disponível em: 〈http://www.if.ufrgs.br/ moreira/mapasport.pdf >. Acesso em: 10 fev. 2015.

OLIVEIRA, Michel Montandon; SAID, Camila; SALES, Shirlei Rezende. A experiência do projeto Escola da Vez: multiletramento digital no ambiente escolar. In: CONGRESSO LATINO AMERICANO DE SOCIOLOGÍA, 29.: 2013, Santiago. [Anais...]. Santiago: [s.n.], 2013. (Crisis e Emergencias Sociales en America Latina).

OLIVEIRA, Michel Montandon. Rodas de diálogo: práticas multimodais de criação colaborativa no Ensino Médio sob a perspectiva da teoria da complexidade. 2014. Dissertação (Mestrado) - Centro Federal de Educação Tecnológica de Minas Gerais, Belo Horizonte, 2014.

PERRENOUD, Philippe. Avaliação: da excelência à regulação das aprendizagens - entre duas lógicas. Porto Alegre: Artmed,1999.

PIMENTA, Selma Garrido; ANASTASIOU, Léa das Graças Camargos. Docência no ensino superior. 4.ed. São Paulo: Cortez, 2010. 279p.

SALES, Shirlei Rezende. Orkut.com.escol@: currículos e ciborguização juvenil. 2010. Tese (Doutorado) - Faculdade de Educação, Universidade Federal de Minas Gerais, Belo Horizonte, 2010.

SALES, Shirlei Rezende. O imperativo da ciborguização no currículo do Ensino Médio. In: MORGADO, José Carlos; SANTOS, Lucíola Licínio de Castro Paixão; PARAÍSO, Marlucy Alves. Estudos curriculares: um debate contemporâneo. Curitiba: CRV, 2013. p.193-207.

SALES, Shirlei Rezende. Tecnologias digitais e juventude ciborgue: alguns desafios para o currículo do Ensino Médio. In: DAYRELL, Juarez; CARRANO, Paulo; LINHARES, Carla. Juventude e Ensino Médio: sujeitos e currículos em diálogo. Belo Horizonte: Editora UFMG, 2014.

SALES, Shirlei Rezende; FERREIRA, Aline Gonçalves; VARGAS, Francielle Alves. Juventude EMdiálogo: tecnologias digitais na extensão universitária. Revista Conexão, Ponta Grossa, v. 11, p. 182-193, 2015.

SALES, Shirlei Rezende et al. Propostas de rodas de diálogo: atividades e oficinas. Belo Horizonte: UFMG, 2014. 75p. 
SIBILIA, Paula. Redes ou paredes: a escola em tempos de dispersão. Rio de Janeiro: Contraponto, 2012.

SILVA, Tomaz Tadeu da. Pedagogia do oprimido versus pedagogia dos conteúdos. In: Documentos de Identidade: uma introdução aos estudos do currículo. Belo Horizonte: Autêntica. 1999, p. 57-64.

VEIGA, Ilma Passos Alencastro; RESENDE, Lúcia Maria Gonçalves de; FONSECA, Marília. Aula Universitária e inovação. In: VEIGA, Ilma; Passos Alencastro; CASTANHO, Maria Eugênia. Pedagogia universitária: a aula em foco. Campinas: Papirus, 2000, p. 161191.

ZABALZA, Miguel A. O ensino universitário: seu cenário e seus protagonistas. Porto Alegre: Artmed, 2004. 239 p.

\section{'Sobre as autoras}

\section{Shirlei Rezende Sales}

E-mail: shirlei.sales@hotmail.com / ORCID: http://orcid.org/0000-0003-4446-9508

Universidade Federal de Minhas Gerais - Brasil

Doutora em Educação pela Universidade Federal de Minhas Gerais

Rafaela Esteves Godinho Leal

E-mail: rafaelegodinho@yahoo.com.br / ORCID: http://orcid.org/0000-0002-1410-6645

Universidade Federal de Minhas Gerais - Brasil

Mestre em Educação pela Universidade Federal de Minhas Gerais [UFMG] 